\title{
As transformações da memória indígena na contemporaneidade
}

\author{
The transformations of indigenous memory in contemporary times
}

\begin{abstract}
Rodrigo Piquet Saboia de Mello
Doutorando pelo Programa de Pós-Graduação em Ciência da Informação do Instituto Brasileiro de Informação em Ciência e Tecnologia - IBICT/UFRJ Chefe do Núcleo de Informação Científica do Museu do Índio E-mail: nuic@museudoindio.gov.br

Ione Helena Pereira Couto Doutora em Memória Social pela Universidade Federal do Estado do Rio de Janeiro - UNIRIO Coordenadora de Patrimonio Cultural do Museu do Índio E-mail: patrimonio.cultural@museudoindio.gov.br
\end{abstract}

\section{Resumo}

O presente artigo apresenta algumas iniciativas do Programa de Documentação de Línguas e Culturas Indígenas PROGDOC, organizado pelo Museu do Índio/Fundação Nacional do Índio em parceria com a Organização das Nações Unidas para a Educação, a Ciência e a Cultura - UNESCO e pelos centros de documentação em áreas indígenas. $\mathrm{O}$ trabalho terá como objetivo principal abordar as transformações da memória indígena: da memória oral, deslocando pela memória documental fomentada pelo Estado e a memória auto-referente, na qual os retratados são os mesmos que realizam a ação documentária, ou seja, os próprios povos indígenas. O contexto político-institucional que ensejou o Programa também será discutido.

Palavras-chave: Programa de Documentação de Línguas e Culturas Indígenas - PROGDOC. Indigenismo. Documentação. Memória. Fundação Nacional do Índio - FUNAI.

\begin{abstract}
This article presents some initiatives of the Programa de Documentação de Línguas e Culturas Indígenas PROGDOC, organized by the Museu do Índio/Fundação Nacional do Índio in partnership with the United Nations Educational, Scientific and Cultural Organization - UNESCO and the centers of documentation in indigenous areas. The main objective of this work will be to deal with the transformations of indigenous memory: from oral memory, shifting through documentary memory fostered by the State and self-referential memory, in which the portrayed are the same ones who perform the documentary action, that is, the peoples themselves Indigenous peoples. The political-institutional context that gave rise to the Program will also be discussed.
\end{abstract}

Keywords: Programa de Documentação de Línguas e Culturas Indígenas - PROGDOC. Indigenism. Documentation. Memory. Fundação Nacional do Índio - FUNAI. 


\section{Introdução}

Nas últimas décadas temos assistido a grandes transformações no que diz respeito à produção documentária e a forma como instituições e sociedade têm se apropriado das informações produzidas e/ou salvaguardadas em repositórios institucionais. Novos tipos de suportes de informação têm surgido, o que nos faz pensar em novos desafios para a sua manutenção, já que não são mais produzidos por uma autoridade documentária, mas sim por agentes autônomos que possuem a capacidade de articular o manejo das novas tecnologias de informação.

O Programa de Documentação de Línguas e Culturas Indígenas - PROGDOC é uma ação do Museu do Índio/Fundação Nacional do Índio em parceria com a Organização das Nações Unidas para a Educação, a Ciência e a Cultura - UNESCO e os povos indígenas e tem como objetivo principal promover o registro das manifestações culturais dos índios do Brasil. Sua principal característica é instrumentalizar os índios na realização de trabalhos de cunho documentário e gerenciamento de centros de documentação em suas terras indígenas. Esse Programa é marcado pela captura digital de registros culturais pelos próprios indígenas, depois de treinados por meio de oficinas promovidas pelo Museu do Índio. Os documentos produzidos pelo Programa são posteriormente inseridos na documentação do Museu e nos centros de documentação indígena gerenciados pelos próprios povos ameríndios.

Para a compreensão do processo que está em curso, o conceito de transmutação da memória indígena é pertinente, porque traz em sua essência o caráter transitório, transformador e metamorfósico da memória indígena marcada, tradicionalmente, pela transmissão tendo como base a oralidade. Ao contrário do que ocorre nas sociedades de tradição escrita, que selecionam o que vai ser preservado nos lugares de memória, como bibliotecas e museus, as sociedades tradicionais, neste aspecto, são desafiadoras, visto que não contavam com museus e bibliotecas (CANDAU, 2012). Deste modo: “O primeiro domínio no qual se cristaliza a memória coletiva dos povos sem escrita é aquele que dá um fundamento - aparentemente histórico - à existência das etnias ou das famílias, isto é, dos mitos de origem ” (LE GOFF, 2003, p. 424).

Num segundo momento, podemos afirmar que a transmissão da memória indígena passou a ocorrer por meio do suporte físico, ou seja, de natureza documental. Este processo de transformação da memória tem sua base na experiência vivida pelos povos indígenas em seu contato sistemático com o modelo de registro utilizado pela sociedade ocidental, em que o 
documento tem poder probatório. Inicialmente promovido pelo contato com as missões religiosas e, posteriormente, pelo Estado. O último, representado pelo Serviço de Proteção aos Índios (SPI), criado em 1910 e findado em 1967, cuja principal característica foi o controle das populações indígenas por meio de um sistema tutelar visando a atender aos interesses do Estado, modelo cujo exercício também realizou o registro das manifestações culturais dos povos em que o Serviço assistia. A produção da memória neste estágio passa pela ação de agentes estatais que agiam em conformidade com as diretrizes do Estado. Interessante registrar que: "A memória, em sua forma mais elaborada, é capaz de articular historicamente o passado, não "como ele efetivamente foi"; mas como uma faísca de esperança que fulgura num momento de perigo, para usar a expressão poética de Walter Benjamin” (FREIRE, 1992, p. 139).

Deste modo, a produção da memória, como naquela registrada em suportes de informação produzidos pelo Estado, não significava o registro da memória indígena, mas sim, o registro promovido pelo Estado sobre as manifestações dos povos indígenas. Tais documentos nada mais eram que uma interpretação das ocorrências nas terras habitadas pelos povos indígenas.

O registro escrito tinha em sua base gerar um maior controle dos corpos, com o fito de criar indivíduos mais disciplinados no contexto de uma estrutura racional e da formação de certa identidade nacional. Assim:

O exame faz também a individualidade entrar num campo documentário: seu
resultado é um arquivo inteiro com detalhes e minúcias que se constitui ao nível dos
corpos e dos dias. O exame que coloca os indivíduos num campo de vigilância situa-
os igualmente numa rede de anotações escritas; compromete-os em toda uma
quantidade de documentos que os captam e os fixam. Os procedimentos de exame são
acompanhados imediatamente de um sistema de registro intenso e de acumulação
documentária. Um "poder de escrita" é constituído como uma peça essencial nas
engrenagens da disciplina. Em muitos pontos, modela-se pelos métodos
tradicionais da documentação administrativa. (FOUCAULT, 1999, p. 213, grifo
nosso)

Um terceiro momento, que estamos chamando de transmutação da memória indígena, se insere no contexto do Programa de Documentação de Línguas e Culturas Indígenas, cuja característica mais significativa se encontra na produção documental pelos próprios indígenas e na criação de centros de documentação em suas áreas. A importância da criação deste repositório documental está em colocar o indígena como protagonista no processo de memorialização de suas ações culturais e das demais atividades inerentes para a formação de sua etnicidade. 
A discussão concentra-se nas apropriações que os povos indígenas estão fazendo dos modelos de registro da memória disponíveis em nossa sociedade e concentradas em instituições de memória, como o Museu do Índio, para criar seus próprios registros, utilizando, para isso, novas tecnologias de informação e comunicação (TICs), novos repositórios e seu gerenciamento. Essa nova memória indígena, que pode ser classificada como auto-referente, é também fruto de uma mudança da postura do Estado em relação à diversidade étnica.

\section{As novas configurações documentárias na formação das memórias indígenas}

Para a discussão das chamadas novas configurações documentárias é importante refletir sobre a necessidade da preservação dos estoques informacionais depositados em repositórios públicos ou geridas por entidades autônomas, como os administrados pelos próprios povos indígenas em seus centros de documentação. Podemos indicar que:

\footnotetext{
Para preservar, precisamos, antes, classificar e colecionar. Por isso temos agentes que detêm o poder legítimo de definir o que faz parte do patrimônio. Esses "guardiães do patrimônio" definem o que é digno de ser preservado. Esses bens, pelo seu caráter único e pelo fato de serem vistos como depositários de uma memória que aponta para a identidade nacional, precisam ser defendidos. (OLIVEN, 2003, p. 77)
}

O Estado, por sua natureza jurídica, sempre orientou a formação de agentes públicos visando os tornarem guardiães da memória, como explanado por Oliven. Formados em áreas afins da memória, esses agentes são designados para formarem coleções que são depositadas em instituições estatais.

Tais coleções, representadas por material bibliográfico e museológicos, por exemplo, foram organizadas com o objetivo de atender aos interesses do Estado, exclusivamente, não levando em conta as necessidades da preservação da memória por grupos que não tinham a permeabilidade necessária para o acesso a políticas públicas que fomentassem novos repositórios que atendessem aos próprios povos indígenas.

Assim se deu o processo dos arquivos do SPI, gerados por agentes públicos tendo como finalidade específica atender a justificativa da existência do ente estatal. Portanto:

\footnotetext{
Os arquivos servem para provar. A prova, a necessidade da prova frente a justiça foi, na sociedade ocidental, a primeira razão da conservação para longa duração de determinados documentos escritos: diplomas merovíngios e carolíngios, atos, títulos etc. Os documentos conservados eram documentos de arquivo porque probatórios, e não o contrário. Só muito mais tarde é que foram reconhecidos a todo documento de arquivo um caráter de autenticidade e um valor probatório a ser preservados. (DELMAS, 2010, p. 21)
} 
$\mathrm{O}$ que orientou num primeiro momento a formação dos arquivos sobre os povos indígenas em diversas localidades do território brasileiro foi à necessidade de controle e prova: sejam os relatórios de atividades executadas pelos indigenistas do SPI junto aos indígenas, passando pela realização do levantamento do patrimônio público alocado nos postos indígenas, o desempenho dos índios em práticas econômicas (extrativistas, pastoril, agrícola e oleira), chegando ao controle da entrada e saída de índios das suas aldeias para prestação de serviço a indústria agrícola local.

As experiências adquiridas ao longo das últimas décadas no campo informacional pelo Estado brasileiro poderão representar um grande aliado não apenas na apropriação pelos povos indígenas dos documentos disponibilizados eletronicamente, como também no desenvolvimento de práticas documentárias realizadas pelos próprios indígenas, com o objetivo de registrar suas manifestações culturais.

Cabe ainda ressaltar que os procedimentos documentários contemporâneos em que são utilizadas novas formas de armazenamento e de tratamento da informação não significam a simplificação dos procedimentos técnicos a serem adotados. Deste modo:

Como sabemos, o aumento exponencial da literatura por um lado e a diversidade de
demandas de informação por outro, incentivou e, até mesmo, provocou ao longo do
tempo o desenvolvimento de estudos e pesquisas no campo da organização do
conhecimento e da representação da informação. Instrumentos, métodos e técnicas de
tratamento da informação se proliferaram. Atualmente, com a introdução das novas
tecnologias de comunicação e informação, o problema do tratamento da informação,
em sua essência continua o mesmo. O que passa a ser diferente são as novas dimensões
das atividades de coleta, arquivamento, busca e acesso à informação/conhecimento.
Continuam a ter especial interesse o desenvolvimento de instrumentos métodos e
técnicas direcionadas a solucionar os aspectos cognitivos, operacionais e práticos de
tratamento da informação. (SOUZA, 2012, p. 3)

Neste novo modelo de construção de instrumentos documentários, como os relacionados à recuperação da informação, se faz necessário amplos esforços para a capacitação e qualificação tanto dos agentes envolvidos na sua organização e disponibilização quanto dos sujeitos nele tratados, no caso, os povos indígenas, grupo social dos mais interessados na difusão das informações contidas naqueles documentos. É necessário que os indígenas estejam devidamente instrumentalizados e empoderados dos conhecimentos necessários para utilizar e aprimorar os recursos informacionais disponíveis, até mesmo criando novos descritores e mecanismos para recuperação da informação visando atender, de modo mais eficaz e eficiente, as especificidades étnicas de cada povo. 


\title{
3. Os povos indígenas e as novas experiências da memória
}

Nesta seção, será discutida a formação da memória e a relação desta com a parcela da sociedade brasileira em estudo. A formação da memória coletiva é um dos maiores constituidores da formação da etnicidade dos povos indígenas. Há uma constante reificação do que é ser indígena em contextos nos quais a oralidade é mais importante, senão a única, forma de transmissão do saber. Sobre o processo de memorização:

\begin{abstract}
A ideia da memória como um armazém é muito antiga, e igualmente tão antiga é a ideia de uma arte que ajude o armazenamento com acuidade, fazendo as opções necessárias mediante rápida percepção das mercadorias acumuladas. O armazém, em todos os textos da ars memorativa, é apresentado como bastante ampliável. Em lugar das poucas coisas que ali conservamos, é possível conseguir, mediante a Arte, nele acumular uma quantidade imensa de noções. (ROSSI, 2010, p. 89-90)
\end{abstract}

Em se tratando de memória indígena, essas formações pluriculturais seriam as únicas com legitimidade para informar sobre o que deve se tornar artefato de memória, o que deve ser guardado e preservado ou esquecido.

O Estado brasileiro ao longo do século XX sempre direcionou a produção documentária sobre os povos indígenas com a finalidade de exercer sobre esta parcela social seu controle. Porém, hoje a concepção é distinta, já que na própria formação jurídica do Estado brasileiro, instituída pela Carta Magna promulgada em 1988, os povos indígenas têm reconhecida sua organização social, suas manifestações culturais e religiosas, não cabendo mais ao Estado a formulação de diretrizes de ação que não seja de seu interesse. Reforça o reconhecimento de autonomia destas populações e auxiliam suas iniciativas da preservação de suas memórias os programas de inclusão social, principalmente os voltados para reconhecimento de seu patrimônio cultural material e imaterial.

O contato dos indígenas de forma sistemática com a nossa sociedade gerou, dentre outras demandas, a vontade do registro escrito e visual. Agregou-se a este fato a importância que o registro físico tem em nossa sociedade como valor probatório. Enredados nesta situação, os povos indígenas passaram a utilizar não apenas a oralidade, mas somaram a seu modelo tradicional de transmissão do conhecimento, outros suportes, agora digitais, visando auxiliar a sua recuperação. Criados dentro deste contexto estão os centros de memória e documentação, organizados nas aldeias ou nas cidades mais próximas das terras indígenas, em que as memórias registradas em desenhos, vídeos, textos ou fotografias ficam armazenadas e acessadas não 
apenas por seu povo, mas por outros povos indígenas, incluídos na rede de parentela e na rede virtual de computadores.

Gerados e gerenciados pelos próprios indígenas, esses centros são autônomos na organização de seus repositórios, o que leva aqueles que tratam repertórios desta natureza, formados e treinados pelo Estado, a abrir mão de sua expertise para assimilar e agregar a sua formação uma nova forma de ver e agir sobre a documentação, ou seja, respeitando a lógica e o interesse dos indivíduos abordados no conjunto documental.

A formação de coleções pelos próprios indígenas pode apontar para um novo modelo de desenvolvimento de coleções, distinto daqueles produzidos pelo Estado ou por organizações que não tenham como protagonista os próprios povos indígenas. Destarte:

\footnotetext{
As coleções se inscrevem num espaço de intermediação, permitindo a perpetuação identitária e simbólica de indivíduos por meio do visível concebido no que acumulam. Quando vistos e experimentados magicamente, os objetos que compõem tais coleções, por representarem mais do que objetos significantes, alçam alguns indivíduos, ou mesmo grupos, ao espaço do divino, no caso, do invisível. (RIBEIRO, 2008, p. 66)
}

Tal proeminência na formação de acervo talvez se dê com maior importância, visto que para se chegar a uma relação de perenidade com o conhecimento produzido, os indígenas tinham, no passado, uma urgência do relato oral com objetivo de não cair no esquecimento partes de suas memórias, principalmente, aquelas que viessem a constituir sua etnicidade. Hoje, com a perenidade do suporte informacional, não há mais a urgência da manutenção da oralidade, visando à preservação do que não pode ser esquecido.

\section{O papel do Estado brasileiro no fomento das novas práticas documentárias para com os povos indígenas}

Hoje, a instituição do Estado brasileiro que garante o cumprimento da política indigenista é a Fundação Nacional do Índio, também conhecida como FUNAI. Dentre as responsabilidades da instituição está em resguardar as manifestações culturais representativas das populações indígenas brasileiras, ação de competência do Museu do Índio.

Porém, sabemos que a criação de políticas públicas que envolvem as populações indígenas não ocorre sem disputas e conflitos na formulação e execução quando colocadas em prática. Uma das principais características da FUNAI nos anos pós a chamada Nova República, ou seja, a partir de 1985, foi o clientelismo. Como explica Pozzobon (1999, p. 294): 
O clientelismo, quaisquer que sejam seus objetivos, gera dois subprodutos nefastos: de um lado, o mau emprego de verbas e, portanto, o emperramento das tarefas obrigatórias do órgão, de outro lado, o descosimento do tecido social que liga as diferentes unidades familiares componentes de um grupo indígena.

Em suma, as práticas clientelistas geravam um mal não apenas a Fundação, mas também aos próprios índios, já que grupos familiares indígenas lutavam internamente para obter privilégios junto a FUNAI. Assim, essa prática fez com que o Estado dilatasse as atribuições inerentes ao órgão frente às demandas das populações indígenas:

A questão de fundo é saber se é possível modificar este estado de coisas através do estabelecimento de uma relação de cooperação com os índios, no lugar da relação clientelista. Em outras palavras, trata-se de saber se é possível, no âmbito do Indigenismo oficial, reorientar a política indigenista para o fomento de projetos sustentáveis, a fim de criar as condições necessárias para que os índios e suas comunidades possam se libertar da condição de clientela mal tratada do Estado. (POZZOBON, 1999, p. 297)

A FUNAI, como afirma o autor, sofreu problemas de ordem estrutural, em diversas áreas de atuação, devido sua incapacidade de formular políticas de cunho sustentável frente às demandas dos povos indígenas, em que o campo documentário não ficou de fora.

As práticas negligentes de cunho documentário também foram alertadas desde os anos de 1970, quando da formulação do Centro de Documentação Etnológica (CDE) no Museu do Índio/FUNAI. Vejamos:

O desinteresse pela sorte da documentação histórica e atual no âmbito da FUNAI é parte de uma visão imediatista e pouco esclarecida sobre os índios e seus problemas que, na organização interna da FUNAI, conduziu ao afastamento e marginalização de um número ponderável de funcionários especializados. (MOREIRA NETO, 1979, p. 15)

Recentemente, ventos de mudança sopraram. O Museu do Índio, instituição de caráter técnico-científico da FUNAI apresentou, no final da década de 1990, ações que garantiriam seu papel na preservação da memória indígena. Isto se deu por meio da aprovação do Plano Plurianual (PPA) da FUNAI e de ações de salvaguarda do patrimônio indígena. Deste modo, garantiu autonomia financeira frente aos revezes políticos e de setores que não desejam uma possível autonomização dos povos indígenas. Deste modo:

Em 1998 a Funai encontrava-se envolvida na elaboração do seu Plano Plurianual (PPA), exigência do Estado para alocação de recursos. Por decisão de sua presidência, a Funai no lugar de apresentar uma proposta de orçamento única, encaminhou várias propostas, organizadas pelos seus departamentos. Na ocasião, a direção do Museu apresentou quatro propostas de planos de ação. A primeira, específica para o Museu do Índio, voltadas para a conservação dos seus acervos, e as demais para revitalizar, registrar e difundir o patrimônio cultural indígena. O valor aprovado era inexpressivo, mas o efeito era enorme porque significava que a União passaria alocar, por um período de 4 anos, recursos para a proteção do patrimônio indígena. A aprovação das 
propostas pelo Museu do Índio no PPA, além de terem possibilitado à direção do Museu ampliar sua atuação e manter seus projetos, auxiliou a Funai na redefinição de seu papel, já que introduzia no seu foco de atuação, em conjunto com a questão fundiária, a questão cultural. (COUTO, 2012, p. 91)

Logo, é possível deduzir que a primeira mudança paradigmática na formulação de uma nova política documentária e cultural para os povos indígenas foi a inclusão do Museu do Índio no Plano Plurianual da FUNAI. A tese levantada por Pozzobon (1999) do clientelismo endêmico em que padecia a instituição indigenista não havia correspondência no Museu do Índio, pois interferências políticas contrárias as diretrizes formuladas pelo Museu do Índio não eram mais possível, frente à estabilidade institucional que o Museu conquistou, devido à inclusão no PPA, que o blindou.

A partir da estabilidade política em virtude da vigência do PPA que incluiu, dentre outras iniciativas, as políticas públicas culturais para os povos indígenas, é possível afirmar que houve novos desdobramentos documentários no sentido de se criar um ambiente favorável para uma execução mais autônoma de práticas documentárias junto aos índios.

Veio ao encontro deste cenário favorável para a criação de novos paradigmas de fomento documentário junto aos povos indígenas, o Decreto $\mathrm{n}^{\circ} 7.056$ publicado pela Presidência da República em 29 de dezembro de 2009. Das mudanças mais significativas está a criação de Comitês Regionais para cada Coordenação Regional, órgão descentralizado da FUNAI, composto por servidores e representantes indígenas locais. O objetivo da criação dos Comitês é permitir uma gestão compartilhada, onde os índios podem pleitear ações de seus interesses. Deste modo, tanto podem sugerir a criação de centros de documentação em suas terras quanto cobrar que projetos voltados para a promoção de sua cultura sejam implantados.

Como de praxe frente a políticas adotadas pelo Estado, a publicação do Decreto trouxe polêmicas, no entanto, representou uma maior autonomia dos povos indígenas. Assim, ensejou que os agentes de transformação e emancipação sejam os próprios indígenas.

As políticas públicas voltadas para os povos indígenas sempre apresentaram como característica modelos de ações, inclusive as que tangem as práticas documentárias, que não contassem com a participação dos povos indígenas. As mudanças citadas possibilitaram que o Museu do Índio, no papel de responsável pelo planejamento e implantação de políticas de viés documentário da FUNAI, criasse um ambiente favorável para o desenvolvimento de práticas documentárias com a efetiva participação dos povos indígenas. 
O resultado desta atmosfera positiva para a formulação de novas práticas documentárias voltadas para os povos indígenas culminou em 2009, com o início do Programa de Documentação de Línguas e Culturas Indígenas - PROGDOC que atuou em mais de 105 aldeias das mais diversas regiões do país, contando com a participação ativa e direta dos indígenas. Tal iniciativa possibilitou o registro de mais de 39 culturas indígenas, beneficiando uma população de aproximadamente 27 mil índios.

Há importantes objetivos na atuação do PROGDOG como promover a documentação de línguas e culturas indígenas, ampliando as possibilidades de sua guarda, consolidar a documentação linguística e cultural no país, formando pesquisadores indígenas e não indígenas e a criação de arquivos digitais em centros de documentação em áreas indígenas, nas aldeias e no Museu do Índio.

O processo em curso de formação de pesquisadores indígenas e da criação de centros de documentação nas localidades onde os índios habitam são dos mais importantes. Na verdade, é algo sui generis, pois os protagonistas da captura de informação, em campo, e o tratamento técnico a ser realizado para manutenção destes repositórios informacionais estão sendo feitos pelos próprios índios. Vejamos:

O filme "Inhu", produzido pelo grupo indígena Kalapalo (MT) e pelo Museu do Índio no âmbito do PROGDOC - Programa de Documentação de Línguas e Culturas Indígenas, foi premiado em $1^{\circ}$ lugar - na categoria Vídeo - no Concurso de Fotografias e Vídeos sobre o Patrimônio Imaterial da América Latina. O evento, realizado em Lima nos dias 13 e 14, nas instalações do Ministério da Cultura do Peru, foi promovido pelo Centro Regional para a Salvaguarda do Patrimônio Cultural Imaterial da América Latina - CRESPIAL e contou com a presença de especialistas em fotografia, vídeo e patrimônio cultural imaterial do Equador, Chile, México e Uruguai. O documentário "Inhu" ganhou o prêmio de 2.500 dolares. (MUSEU DO ÍNDIO, 2012, p. 1)

Grandes desafios se apresentam para a consolidação das práticas documentárias efetivadas pelos povos indígenas, práticas estas que refletem o desejo destes povos para a conservação e manutenção de suas memórias, daí que o Programa procura oferecer um meio para sua efetivação. Neste aspecto, o Programa beneficia tanto os povos indígenas quanto a comunidade científica, uma vez que o seu projeto introduz e difundi novas práticas no campo da Linguística e documentário, inclusive de caráter experimental, por ser um trabalho inovador frente à tradição da documentação para com os povos indígenas, já que há a participação ativa do componente indígena na execução do trabalho. 
cada língua documentada, disponibilização dos materiais digitalizados, elaboração de materiais didáticos e para-didáticos, dentre outros. (UNESCO, 2008, p. 10)

O Programa, além de produzir conhecimentos sobre os povos indígenas, os instrumentaliza para documentar a sua própria língua e cultura, permitindo assim uma autonomização dos agentes nas localidades indígenas. Deste modo, permite o acesso ao conhecimento produzido no âmbito acadêmico em sintonia com os saberes tradicionais formulados pelos povos indígenas. Assim, o produto do conhecimento gerado nas localidades habitadas pelos índios estará disponível para os mesmos, por meio dos centros de documentação indígena.

Esta ação documentária de autonomização dos povos indígenas produziu diversos resultados. Dentre os resultados obtidos podemos salientar: a realização de 138 oficinas nas aldeias, abrangendo 128 aldeias e a formação de 95 pesquisadores indígenas em documentação linguística, pesquisa e registro de aspectos de suas culturas, sendo 60 bolsistas.

\section{Conclusão}

Os povos indígenas passam por um período de grandes transformações no seio das suas comunidades, como também na relação com o Estado por meio da instituição oficial que trata sobre a questão indígena: a FUNAI. Os desafios são de grande magnitude, porém se faz necessário uma profunda reflexão do papel que o órgão indigenista terá nos anos vindouros. Podemos conceber que estão em curso importantes modificações da memória indígena.

Deste modo, há uma reconfiguração das memórias indígenas, imersa num universo contemporâneo de incertezas e novas demandas informacionais. Os povos indígenas vão encontrar outros desafios que venham a responder as novas demandas não apenas por informação, mas como também pela possibilidade de acesso à saúde, educação e aos seus territórios com mais qualidade e melhores condições de sobrevivência. $\mathrm{O}$ desafio deste processo metamórfico está na incorporação dos novos elementos tecnológicos e culturais que venham ao encontro dos desejos dos povos indígenas.

A débâcle do indigenismo oficial que se configurava em relações de clientelismo e assistencialismo junto aos povos indígenas estão findando. Nas novas configurações da política indigenista e das ações documentárias implantadas pelo Estado para além do lumpen- 
indigenismo, os indígenas se tornam protagonistas, não apenas na documentação da sua cultura, como também no manejo das novas tecnologias de informação e comunicação.

As formações de centros de documentação em áreas indígenas, apesar de louvável, necessitam de um fomento em longo prazo para que haja investimentos financeiros permanentes tanto por meio de parceiros ativos quanto do próprio Estado brasileiro.

Outro desafio que emerge do contexto histórico de novas práticas documentárias diz respeito à manutenção dos quadros formados no âmbito do Programa. Estes índios, especialistas em documentação, devem ser incentivados a permanecerem em suas aldeias e fomentarem novas práticas informacionais que visem a melhorar as condições dos grupos indígenas.

Até mesmo no âmbito jurídico-institucional, as inovações estabelecidas nos últimos tempos com uma maior disseminação de material sobre a temática indígena, permitirá a revisão de contendas judiciais como também poderá melhor amparar outras ações judiciais de cunho restitutivo pelo Ministério Público Federal (MPF) ou até mesmo oferecer subsídios a futura Comissão Nacional Indígena da Verdade, exclusiva para o estudo de graves violações de direitos humanos contra os povos indígenas.

As ações que o Museu do Índio tem desenvolvido nas últimas décadas se coadunam com uma ação formulada pelo Estado brasileiro por meio da FUNAI, ou seja, investido na constante autonomia dos índios, visando seu fortalecimento frente às contundentes mudanças que se encontram em curso que, dentre elas, podemos citar a Proposta de Emenda à Constituição (PEC) 215/00 que submete a aprovação da demarcação de terras indígenas ao Congresso Nacional, um retrocesso dos direitos alcançados pelas populações indígenas, visto que procura beneficiar grupos econômicos que anseiam por acesso a áreas com alto valor agregado, ricas em recursos hídricos, florestais e minerais.

Mais do que a ação constante do Estado brasileiro, em cumprimento aos dispositivos constitucionalmente previstos na Carta Magna promulgada em 1988, somente por meio da qualificação dos povos indígenas, pela valorização de sua cultura material e imaterial, mas principalmente pela existência e valorização da documentação, é que os povos indígenas espalhados em todo o território nacional estarão instrumentalizados para enfrentar inúmeros desafios.

Ainda não sabemos em que direção será conduzida a política indigenista formulada pelo Estado brasileiro e qual transmutação da memória advirá deste processo, porém, podemos 
esperar que sopros de autonomia numa dinâmica de auto-suficiência dos povos indígenas estão por vir.

\section{Referências}

CANDAU, J. Memória e identidade. São Paulo: Contexto, 2012.

COUTO, I. H. P. A política institucional e o trabalho curatorial na montagem da exposição “Tempo e Espaço no Amazonas: os Wajãpi”. In: QUESTÕES indígenas e museus: debates e possibilidades. Brodowski: ACAM Portinari; Museu de Arqueologia e Etnologia da Universidade de São Paulo; Secretaria de Estado da Cultura, 2012. p. 90-95.

DELMAS, B. Arquivos pra quê?: textos escolhidos. São Paulo: Instituto Fernando Henrique Cardoso, 2010.

FREIRE, J. R. B. Tradição oral e memória indígena: a canoa do tempo. In: AMÉRICA: descoberta ou invenção: Rio de Janeiro: Imago, 1992. p. 138-164.

FOUCAULT, M. Vigiar e punir: nascimento da prisão. Petrópolis: Vozes, 1999.

LE GOFF, J. História e memória. Campinas: Ed. da UNICAMP, 2003.

MOREIRA NETO, C. A. Centro de Documentação Etnológica da FUNAI. Arquivo \& Administração, Rio de Janeiro, v. 7, n. 2, p. 12-15, maio/ago. 1979.

MUSEU DO ÍNDIO. Boletim informativo ProgDoc. Rio de Janeiro, ano 4, n. 43, p. 1, nov. 2012.

OLIVEN, R. G. Patrimônio intangível: considerações iniciais. In: ABREU, R.; CHAGAS, M. (Org.). Memória e patrimônio: ensaios contemporâneos. Rio de Janeiro: DP\&A, 2003. p. 77-80.

POZZOBON, J. O lumpen-indigenismo do estado brasileiro. Journal de La Société des Américanistes, t. 85, p. 281-306, 1999.

RIBEIRO, L. B. Patrimônio visual: as imagens como artefatos culturais. In: DODEBEI, V.; ABREU, R. (Org.). E o patrimônio?. Rio de Janeiro: Contra Capa, 2008. p. 59-71.

ROSSI, P. O passado, a memória, o esquecimento: seis ensaios da história das ideias. São Paulo: Ed. da UNESP, 2010.

SOUZA, R. F. Organização do conhecimento. In: TOUTAIN, L. M. B. B. Para entender a Ciência da Informação. Salvador: EDUFBA, 2012. p. 103-124.

UNESCO. Projeto de cooperação técnica internacional: documentação de línguas e culturas indígenas brasileiras. Brasília, DF: UNESCO, 2008. 